\title{
Examining the $\mathrm{Gm} 18$ and $\mathrm{m}^{1} \mathrm{G}$ Modification Positions in tRNA Sequences
}

\author{
Mayavan Subramanian $^{1 \dagger}$, Thangavelu Srinivasan ${ }^{2 \dagger}$, Dorairaj Sudarsanam ${ }^{2 *}$ \\ ${ }^{1}$ Synthetic Biology and Biofuel Group, International Center for Genetic Engineering and Biotechnology (ICGEB), \\ New Delhi 110 067, India, ${ }^{2}$ DST-FIST Bioinformatics and Principal Investigator, School of Genomics and Bioinformatics, \\ Department of Advanced Zoology and Biotechnology, Loyola College, Chennai 600 034, India
}

\begin{abstract}
The tRNA structure contains conserved modifications that are responsible for its stability and are involved in the initiation and accuracy of the translation process. tRNA modification enzymes are prevalent in bacteria, archaea, and eukaryotes. tRNA Gm18 methyltransferase (TrmH) and tRNA $m^{1} \mathrm{G} 37$ methyltransferase (TrmD) are prevalent and essential enzymes in bacterial populations. TrmH involves itself in methylation process at the $2^{\prime}-\mathrm{OH}$ group of ribose at the 18 th position of guanosine (G) in tRNAs. TrmD methylates the $G$ residue next to the anticodon in selected tRNA subsets. Initially, $m^{1} G 37$ modification was reported to take place on three conserved tRNA subsets (tRNA ${ }^{\text {Arg }}$, tRNA ${ }^{\text {Leu }}$, tRNA ${ }^{\text {Pro }}$ ); later on, few archaea and eukaryotes organisms revealed that other tRNAs also have the $\mathrm{m}^{1} \mathrm{G} 37$ modification. The present study reveals $\mathrm{Gm} 18, \mathrm{~m}^{1} \mathrm{G} 37$ modification, and positions of $m^{1} G$ that take place next to the anticodon in tRNA sequences. We selected extremophile organisms and attempted to retrieve the $\mathrm{m}^{1} \mathrm{G}$ and $\mathrm{Gm} 18$ modification bases in tRNA sequences. Results showed that the

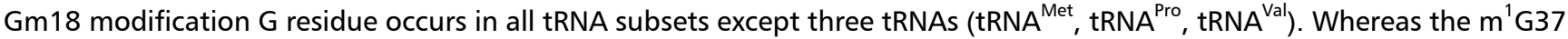
modification base $\mathrm{G}$ is formed only on tRNA ${ }^{\mathrm{Arg}}$, $\mathrm{TRNA}^{\mathrm{Leu}}$, $\mathrm{tRNA}^{\mathrm{Pro}}$, and tRNA ${ }^{\text {His }}$, the rest of the tRNAs contain adenine (A) next to the anticodon. Thus, we hypothesize that $\mathrm{Gm} 18$ modification and $\mathrm{m}^{1} \mathrm{G}$ modification occur irrespective of a $\mathrm{G}$ residue in tRNAs.
\end{abstract}

Keywords: anticodon, $\mathrm{Gm} 18$ and $\mathrm{m}^{1} \mathrm{G}$ modification sites, tRNA subsets

\section{Introduction}

Marinobacter species is one of the most ubiquitous classes formed in the marine ecosystem. It occurs throughout the water column in deep oceans, and it exerts a significant impact on various biogeochemical cycles. Marinobacter aquaeolei is involved in redox reactions that utilize oxygen and nitrate as terminal electron acceptors [1]. It exhibits hydrocarbon-degrading mechanisms and is capable of diverse extremophilic attributes (psychrophily, oligotrophy, and halotolerance) [2]. Marinomonas MWYL1 is able to grow on the betaine molecule and use dimethylsulfoniopropionate (DMSP) as their sole carbon source. Dimethyl sulphide is released as a by-product of metabolism of DMSP and reaches the atmosphere, which subsequently forms cloud condensation nuclei during oxidation [3]. The key gene $(d d d D)$ in M. MWYL1 encodes for acetyl-CoA transferase, which adds CoA to DMSP, prior to its subsequent cleavage [4]. Thus, M. MWYL1 is involved in the cycling of the climate-changing gas DMS, and their genomic potential still needs to be unraveled. Nitrobacter hamburgensis, a gramnegative bacterium, forms a biofilm, which is considered a suitable alternative for the treatment of wastewater that otherwise requires large and expensive reactors for efficient bioremediation [5]. Nitrobacter winogradskyi inhabits many soil types, natural stones, as well as both fresh and salt water. It derives its energy at once through nitrite oxidation and carbon dioxide fixation, thus acting as a chemolithoautotroph. The gammaproteobacterium class of Nitrosococcus oceani is an obligate chemolithoautotroph capable of extracting energy and reducing power from the oxidation of

${ }^{\dagger}$ These two authors contributed equally to this work. 
ammonia to nitrite. $N$. oceani's impact on the ecosystem is the massive release of nitrogen oxide and nitrogen gases into the atmosphere, thus completing the nitrification cycle. It also contributes to the maintenance of concentrations of nitrate in the nitrogen pool of the deep ocean at $40 \mu \mathrm{M}$ [6].

\section{Insight into tRNA modifications}

tRNA is a small chain of nucleotides that decipher the genetic code to protein synthesis on codon and anticodon interactions and has a potential role in DNA repair mechanism tRNA methyltransferase brings changes in the nucleosides in the tRNA structure. Recently, some of these nucleoside modifications have been reported to be involved in the cell response to environmental stress and in the repair of DNA damage as well. In many cases, the posttranscriptional modification of tRNA has facilitated translation of deviant sense codons [7], and these modifications are essential for tRNA folding function. The amino acyl tRNA synthetase recognizes the cognate tRNA through their structure and chemistry, contributed by modified nucleosides at the anticodon loop [8]. Thus, the modification of stem and loop structures of tRNAs regulates gene expression by ordering conformation and dynamics for recognition of the codon and maintenance of the reading frame. Similarly, mRNAs are programmed to shift their frame when there is no modification in tRNA [8]. In an actively dividing cell, tRNA gene content determines the relative abundance of tRNA isoacceptor, which, in turn, determines codon translation efficiency [9]. The relative abundance of a particular tRNA isoacceptor is kingdomspecific, and enzymes present in the organism increase the translational efficiency of codons through modification in the anticodon wobble base. It implies that the modified enzymes play a major role in the evolution of genomic composition [9]. Methylation reactions account for the majority of posttranscriptional modifications in tRNA [10]. tRNA methyltransferase (Trm) catalyzes the modification along the length of tRNA, including at the anticodon site. Indeed, Trm has a potential and crucial role in enhancing the synthesis of proteins that participate in the damage response [11].

\section{tRNA Gm18 methyltransferase (TrmH)}

To date, 150 modified nucleosides have been identified in RNA, and in tRNA alone 92 such modifications have been recorded [12]. Prominent among those are 2'-OH ribose methylated nucleoside, which is commonly found in tRNAs. The posttranscriptional modification in RNA is mediated through specific methyltransferase enzymes [13]. These modifications can occur in the noncoding region of the RNA sequences. In fact, tRNA contains abundant modified nucleosides, which stabilize the L-shaped tRNA structure and improves their molecular recognition [14]. A conserved guanosine is present at position 18 in the D loop of t-RNA modified to 2'-OH methyl guanosine. This modification stabilizes the L-shaped structure of t-RNA by interacting with pseudouridine 55 [15]. The enzyme TrmH catalyzes the reaction through transfer of a methyl group from Sadenosyl-methionine (AdoMet) to the 2'-OH group of the G18 ribose in tRNA D-loops [16]. The TrmH gene in Escherichia coli [17], Thermus thermophilus [18], and Aquifex aeolicus [19] has been identified to have similar catalytic motifs in them. TrmH is subdivided into two classes based on their substrate tRNA specificity. The type I enzymes are involved in the modification of all tRNA species, whereas type II modifies only a subset of tRNA species [20]. The Gm18 modification contributes towards defense reactions during pathogen encounters and has been observed in high frequency both in eukaryotes and prokaryotes, including viral RNA [21]. Therefore, a Gm18 modification study gains a significant factor of an infectious microbe, as it acts as a toll-like receptor 7 antagonist [21], and it can be utilized as an anti-inflammatory drug as well [20].

\section{tRNA m $^{1}$ G37 methyltransferase (TrmD)}

Lots of modified nucleosides are present at the region of anticodons, specifically at positions 34 (the wobble position) and 37 ( 3 ' and adjacent to the anticodon). One of them is the 1-methyl guanosine $\left(\mathrm{m}^{1} \mathrm{G}\right)$ modification occurring at position 37 in tRNA [22]. This modification is catalyzed by TrmD, which catalyzes the addition of a methyl group from AdoMet to $\mathrm{G}$ at position 37, adjacent to the anticodon [23]. The specificity of this enzyme is determined by $\mathrm{V}, \mathrm{T}$, and $\mathrm{D}$ side loops and the presence of a G36pG37 sequence [24]. TrmD is a vital enzyme for maintaining the correct reading frame during translation [25]. Lack of this modification at the 37 th position (i.e., next to the anticodon) leads to $\mathrm{a}+1$ frameshift and hinders the translation efficiency [26]. The nucleus-encoded tRNA is methylated at $\mathrm{G}$ before being transported to the cytoplasm, whereas in mitochondria, the tRNA is methylated at G37 by a nucleus-encoded enzyme and transported into organelles [27]. Both TrmH and TrmD enzymes are under the class of the SpoU family and share similar catalytic reactions [28]. Hence, the study confirms that tRNA subsets contain $G$ bases at the 18th position (D-loop) and next to the anticodon (anticodon loop).

\section{Methods}

FASTA format of tRNA gene sequences of $M$. aquaeolei, $M$. MWYL1, N. hamburgensis, $N$. winogradskyi, and $N$. oceani were retrieved from a tRNA database (http://gtrnadb.ucsc.edu/) [29] 
Table 1. Amino acid-specific tRNAs that lack a $G$ residue at the 18th and 38th positions

\begin{tabular}{|c|c|c|c|c|}
\hline $\begin{array}{l}\text { Sample } \\
\text { No. }\end{array}$ & Organisms & No. of tRNAs & $\begin{array}{l}\text { tRNAs do not have a } G \text { residue } \\
\text { at the } 18 \text { th position }\end{array}$ & $\begin{array}{l}\text { G residue at the 38th } \\
\text { position in tRNAs }\end{array}$ \\
\hline 1 & Marinobacter aquaeolei & 51 & 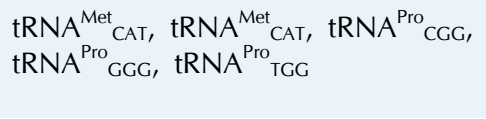 & 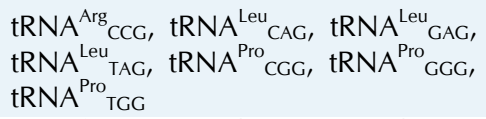 \\
\hline 2 & Marinomonas MWYL1 & 83 & 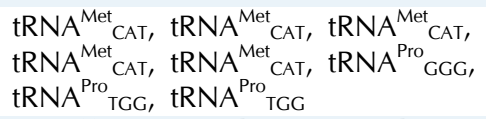 & 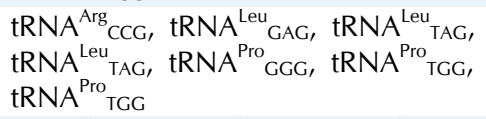 \\
\hline 3 & Nitrobacter hamburgensis & 50 & 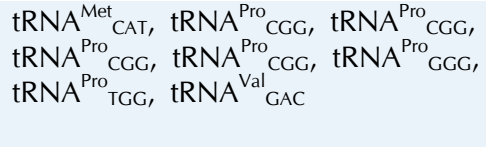 & 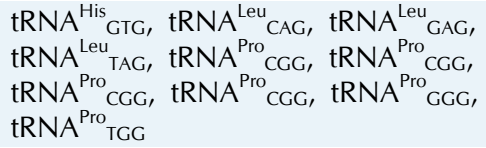 \\
\hline 4 & Nitrobacter winogradskyi & 47 & $\begin{array}{l}\text { tRNA }{ }^{\text {Met }}{ }_{C A T}^{\text {PT, tRNA }}{ }_{\text {PGG, }}^{\text {Pro }} \text { tRNA }{ }_{\text {GGG, }}^{\text {Pro }} \\
\text { tRNA }{ }_{\text {TGG }}\end{array}$ & 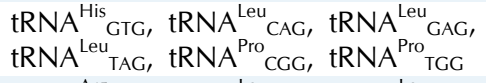 \\
\hline 5 & Nitrosococcus oceani & 45 & $\begin{array}{l}\text { tRNA }^{\text {Met }}{ }_{\text {MAT, }} \text { tRNA }{ }^{\text {Pro }}{ }_{\text {CGG, }} \text { tRNA }{ }_{\text {PGG, }}^{\text {Pro }} \\
\text { tRNA }^{\text {Pro }}{ }_{\text {TGG }}\end{array}$ & 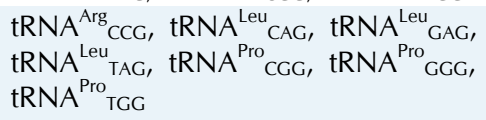 \\
\hline
\end{tabular}

and used for multiple sequence alignment by BioEdit software (http://www.mbio.ncsu.edu/bioedit/bioedit.html) [30].

\section{Results}

The presence of Gm18 modification bases were analyzed in total tRNAs of M. aquaeolei, M. MWYL1, N. hamburgensis, N. winogradskyi, and $N$. oceani. These organisms' tRNA contains a $\mathrm{G}$ residue at the 18th position adjacent to the anticodon loop, except tRNA ${ }^{\mathrm{Met}}$, tRNA ${ }^{\text {Pro }}$, and tRNA ${ }^{\mathrm{Val}}$ (Table 1). Furthermore, the 18th position of tRNAs in M. aquaeolei (51 tRNAs) and M. MWYL1 (83 tRNAs) contain thymine (T), cytosine (C), or adenine (A) instead of $\mathrm{G}$ residue. M. aquaeolei's tRNA $^{\text {Met }}{ }_{\text {CAT }}$ (two copies), tRNA ${ }^{\text {Pro }}{ }_{\text {CGG, tRNA }}{ }_{\text {Pro }}{ }_{\text {CGG, and }}$ tRNA $^{\text {Pro }}$ TGG have T instead of G residues. M. MWYL1 contains 9 copies of tRNA ${ }^{\text {Met }}$ CAT; of these, six tRNAs have a T residue at the 18th position and three contain a $G$ residue at the 18 th position. Only three proline-specific tRNAs are formed in $M$. MWYL1, and all of them show a $\mathrm{T}$ base at the 18th position instead of G. The organism N. hamburgensis comprises 50 tRNA subsets; among these, eight tRNAs showed no G residue at the 18th position, and the rest of the 42 had a $G$ residue. Thus, the tRNAs without $G$ residues are $t R N A^{\text {Met }}{ }_{\text {CAT, }}$, tRNA ${ }_{\text {PGG }}^{\text {Pro }}$ (three copies), tRNA ${ }_{\text {GGG, }}^{\text {Pro }}$ tRNA $^{\text {Pro }}{ }_{\text {TGG, }}$ and tRNA $^{\mathrm{Val}}$ GAC. Therefore, eight tRNAs at the 18th position show $\mathrm{T}, \mathrm{C}$, or $\mathrm{A}$. Besides tRNA ${ }_{\text {CAT, }}^{\text {Met }} \mathrm{RNA}^{\text {Pro }}{ }_{\mathrm{CGG}}$ and tRNA $^{\text {Pro }}{ }_{\text {GGG }}$ show a $\mathrm{C}$ residue, and $\mathrm{tRNA}^{\text {Pro }}{ }_{\mathrm{CGG}}$ and tRNA $^{\text {Pro }}$ TGG hold a $T$ residue at the 18th position. Nevertheless, tRNA ${ }_{\text {GAC }}$ confirmed an A residue at the 18th position. Among six proline-specific tRNAs ( $t R N A^{\text {Pro }}{ }_{\mathrm{CGG}}$ ), only one showed a $\mathrm{G}$ residue at the 18 th position. Furthermore, N. winogradskyi and $N$. oceani revealed 47 and 45 tRNAs, respectively. These two organisms hold similar properties - i.e., tRNA subsets, like tRNA ${ }^{\text {Met }}$ CAT, tRNA ${ }_{\text {CGG, }}^{\text {Pro }}$ $\mathrm{tRNA}_{\text {GGG}}^{\text {Pro }}$, and tRNA ${ }_{\text {TGG }}^{\text {Pro }}$, containing a $\mathrm{T}$ residue at the 18 th position as a substitute for the $G$ residue.

\section{Locating guanosine next to the anticodon in tRNAs}

M. aquaeolei, M. MWYL, N. hamburgensis, N. winogradskyi, and $N$. oceani have common conserved tRNA subsets $\left(\mathrm{tRNA}^{\mathrm{Arg}}\right.$, $\mathrm{tRNA}^{\mathrm{Leu}}$, and $\mathrm{tRNA}{ }^{\mathrm{Pro}}$ ) that contain a $\mathrm{G}$ residue at the 38th position (G37pG38) next to the anticodon. Variations of the $\mathrm{G}$ residue in archaea Methanococcus jannaschii tRNAs, such as tRNA ${ }^{\text {Cys }}$ (G35pG36); tRNA ${ }^{\text {His }}$, and tRNA ${ }^{\text {Arg }}$ (G36pG37); tRNA ${ }^{\text {Gln }}$ and tRNA ${ }^{\text {Try }}$ (G37pG38); tRNA ${ }^{\text {Arg }}$, tRNA $^{\text {Pro }}$, and tRNA ${ }^{\text {Ser }}$ (G37pG39); tRNA ${ }^{\text {Leu }}$, tRNA ${ }^{\text {Glu }}$, $\mathrm{tRNA}^{\text {Trp }}$, tRNA ${ }^{\text {Ser }}$, and tRNA ${ }^{\text {Pro }}$ (G39pG40) [31] are already revealed. M. aquaeolei, M. MWYL1, and N. hamburgensis share similar tRNA subsets (tRNA ${ }^{\text {Arg }}, \mathrm{tRNA}^{\mathrm{Leu}}$, and $\mathrm{tRNA}^{\text {Pro }}$ ) that contain a $G$ residue at the 38 th position (G37pG38) next to the anticodon (Table 1). N. winogradskyi loses the $G$ residue in $\mathrm{tRNA}^{\mathrm{Arg}}$, but it has presented it at the 38th position in

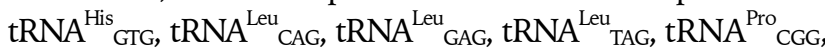
tRNA ${ }_{\text {GGG }}^{\text {Pro }}$, and tRNA ${ }_{\text {TGG. }}^{\text {Pro }}$. oceani contains conserved tRNAs (tRNA ${ }^{\text {Arg }}{ }_{C C G}$, tRNA ${ }^{\text {Leu }}{ }_{C A G}, t_{R N A}{ }^{\text {Leu }}{ }_{\text {GAG }}, t_{R N A}{ }^{\text {Leu }}{ }_{\text {TAG }}$, tRNA ${ }_{\text {CGG }}^{\text {Pro }}$ tRNA ${ }_{\text {Pro }}^{\text {Pro }}$, tRNA ${ }_{\text {TGG }}^{\text {Pro }}$ in which the $G$ residue (G37pG38) is presented next to the anticodon (Table 1). An interesting finding is that tRNAMet and tRNAPro are the only two tRNA copies that do not have a G residue at 18th position in all of these organisms (Fig. 1). Additionally, the $\mathrm{tRNA}^{\mathrm{Arg}}, \mathrm{tRNA}^{\mathrm{Leu}}$, and $\mathrm{tRNA}^{\mathrm{His}}$ share common properties, except tRNA ${ }^{\text {Pro }}$. But, tRNA ${ }^{\text {Pro }}$ has a $G$ residue at the 18 th and 38th positions in these five organisms (Fig. 2). 


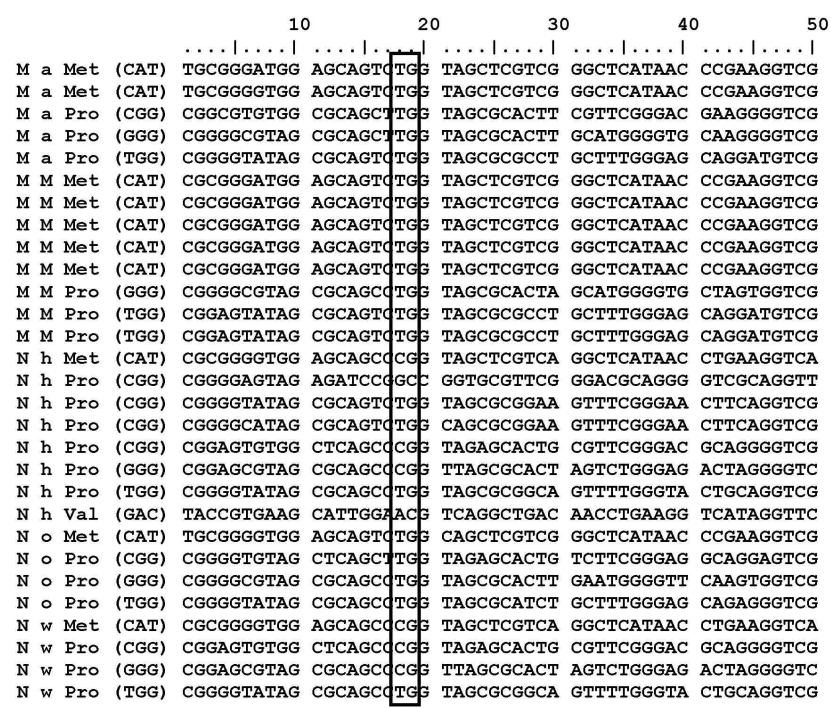

Fig. 1. tRNAs sequences are marked at 18 th positions, in all organism where tRNA ${ }^{\text {Met }}$ and $t R N A^{\text {Pro }}$ sequences hold $A$, $T$ or $C$ instead of $\mathrm{G}$ at 18th position.

\section{Discussion}

It is proposed that G18 modification base occurrence and non-occurrence in tRNA subsets in Marinobacter is attributed to the inhabitably extreme environments (M. aquaeolei, $M$. MWYL1), including chemolithotropic N. hamburgensis, $N$. winogradskyi, and $N$. oceani. Thus, a notable finding is that only methionine- and proline-specific tRNAs do not have a G residue at the 18th position, and even its absence at the 18th position does not hamper the possibility to methylate the 2 '-OH group of ribose in tRNAs. It might be a modified Gm18 base (D loop) that interacts with a $\psi 55$ tertiary base (T loop) for conformational rigidity of the tRNA structure [32]. Another finding is the $\mathrm{m}^{1} \mathrm{G}$ modification site in tRNAs, in which it was previously reported that only three types of tRNAs (tRNA ${ }^{\text {Arg }}$, $\mathrm{tRNA}^{\mathrm{Leu}}$, and tRNA ${ }^{\mathrm{Pro}}$ ) held a G base next to the anticodon $[22,33]$. Later, the $\mathrm{m}^{1} \mathrm{G}$ modification was reported in additional tRNAs, such as tRNA ${ }^{\mathrm{Gln}}$ in archaea and tRNA ${ }^{\text {Asp }}$ in eukaryotes [34]. A study reported tRNA ${ }^{\text {Gln }}$ with $\mathrm{m}^{1} \mathrm{G}$ in Mycobacterium tuberculosis H37Rv, $\mathrm{RRNA}^{\mathrm{Phe}}$ with $\mathrm{m}^{1} \mathrm{G}$ in Staphylococcus aureus MRSA252, and Streptococcus pneumoniae D39 [31]. The Gm18 modification base $\mathrm{G}$ is conserved in these five organisms. For instance, $\mathrm{tRNA}^{\mathrm{Met}}$ and $\mathrm{tRNA}^{\text {Pro }}$ sequences do not have a $G$ residue at the 18 th position. Furthermore, the $N$. hamburgensis organism does not have a $G$ residue in $t R N A_{\text {GAC. The }}^{\mathrm{Val}}{ }^{1} G$ and its location are highly conserved and located at the 38th position in tRNAs. Mostly the purine bases $\mathrm{G}$ or $\mathrm{A}$ are placed next to the anticodon in all tRNAs. This modification may influence the codon-anticodon interaction in the translation process [35].

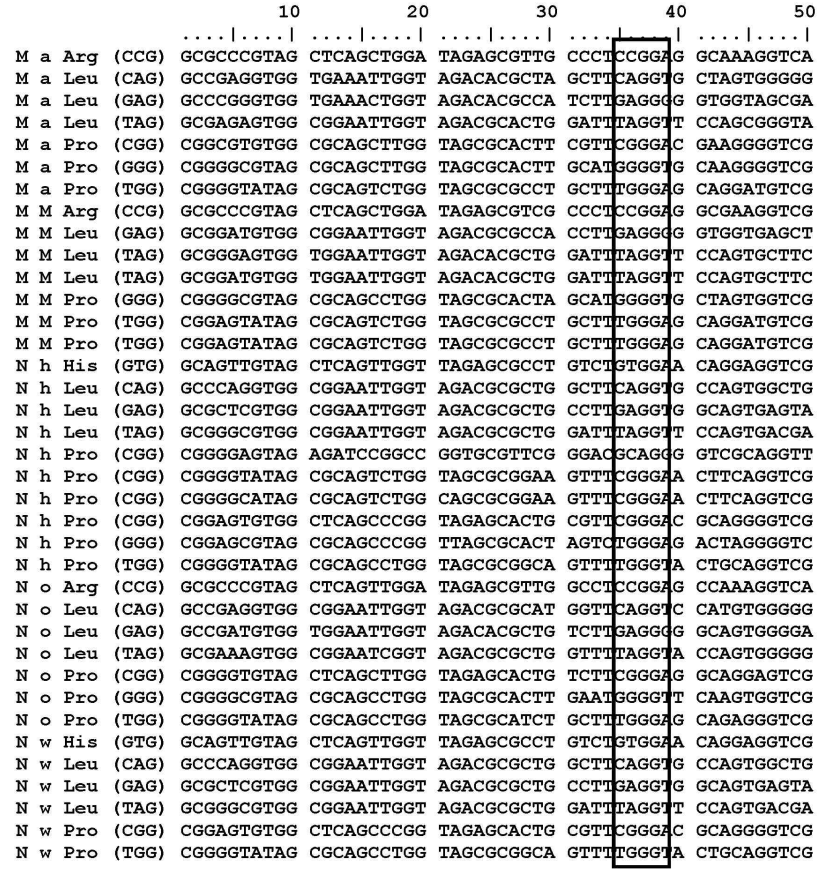

Fig. 2. tRNA sequences with $G$ residue occur at 38th position next to the anticodon (G37pG38 sequence).

These findings suggest that either these two modifications are not necessary to occur in all tRNAs or might occur with/without $\mathrm{G}$ residues at the respective positions. Hence, we conclude that the Gm18 modifications and $\mathrm{m}^{1} \mathrm{G} 37$ tRNAs are essential in all three domains and have revealed a conserved tRNAs with $\mathrm{m}^{1} \mathrm{G} 37$ in a few marine and chemolithoautotrophs. Further study is called for to include more marine and extremophiles to gain insights into tRNA modification bases and their role in biological processes.

\section{References}

1. Singer E, Webb EA, Nelson WC, Heidelberg JF, Ivanova N, Pati A, et al. Genomic potential of Marinobacter aquaeolei, a biogeochemical "opportunitroph". Appl Environ Microbiol 2011;77: 2763-2771.

2. Huu NB, Denner EB, Ha DT, Wanner G, Stan-Lotter H. Marinobacter aquaeolei sp. nov., a halophilic bacterium isolated from a Vietnamese oil-producing well. Int $J$ Syst Bacteriol 1999;49(Pt 2):367-375.

3. Charlson RJ, Lovelock JE, Andreae MO, Warren SG. Oceanic phytoplankton, atmospheric sulphur, cloud albedo and climate. Nature 1987;326:655-661.

4. Todd JD, Rogers R, Li YG, Wexler M, Bond PL, Sun L, et al. Structural and regulatory genes required to make the gas dimethyl sulfide in bacteria. Science 2007;315:666-669.

5. Franco-Rivera A, Paniagua-Michel J, Zamora-Castro J. Characterization and performance of constructed nitrifying biofilms during nitrogen bioremediation of a wastewater 
effluent. J Ind Microbiol Biotechnol 2007;34:279-287.

6. Klotz MG, Arp DJ, Chain PS, El-Sheikh AF, Hauser LJ, Hommes NG, et al. Complete genome sequence of the marine, chemolithoautotrophic, ammonia-oxidizing bacterium Nitrosococcus oceani ATCC 19707. Appl Environ Microbiol 2006;72: 6299-6315.

7. Cantara WA, Murphy FV 4th, Demirci H, Agris PF. Expanded use of sense codons is regulated by modified cytidines in tRNA. Proc Natl Acad Sci U S A 2013;110:10964-10969.

8. Gustilo EM, Vendeix FA, Agris PF. tRNA's modifications bring order to gene expression. Curr Opin Microbiol 2008;11:134140.

9. Novoa EM, Pavon-Eternod M, Pan T, Ribas de Pouplana L. A role for tRNA modifications in genome structure and codon usage. Cell 2012;149:202-213.

10. Unal E, Arbel-Eden A, Sattler U, Shroff R, Lichten M, Haber JE, et al. DNA damage response pathway uses histone modification to assemble a double-strand break-specific cohesin domain. Mol Cell 2004;16:991-1002.

11. Begley TJ, Samson LD. Network responses to DNA damaging agents. DNA Repair (Amst) 2004;3:1123-1132.

12. Rodriguez-Hernandez A, Spears JL, Gaston KW, Limbach PA, Gamper H, Hou YM, et al. Structural and mechanistic basis for enhanced translational efficiency by 2-thiouridine at the tRNA anticodon wobble position. J Mol Biol 2013;425:38883906.

13. Kiss-Laszlo Z, Henry Y, Bachellerie JP, Caizergues-Ferrer M, Kiss T. Site-specific ribose methylation of preribosomal RNA: a novel function for small nucleolar RNAs. Cell 1996;85: 1077-1088.

14. Juhling F, Mörl M, Hartmann RK, Sprinzl M, Stadler PF, Pütz J. tRNAdb 2009: compilation of tRNA sequences and tRNA genes. Nucleic Acids Res 2009;37:D159-D162.

15. Kim SH, Suddath FL, Quigley GJ, McPherson A, Sussman JL, Wang AH, et al. Three-dimensional tertiary structure of yeast phenylalanine transfer RNA. Science 1974;185:435-440.

16. Kumagai I, Watanabe K, Oshima T. Thermally induced biosynthesis of 2'-O-methylguanosine in tRNA from an extreme thermophile, Thermus thermophilus HB27. Proc Natl Acad Sci U S A 1980;77:1922-1926.

17. Gustafsson C, Reid R, Greene PJ, Santi DV. Identification of new RNA modifying enzymes by iterative genome search using known modifying enzymes as probes. Nucleic Acids Res 1996;24:3756-3762.

18. Hori H, Yamazaki N, Matsumoto T, Watanabe Y, Ueda T, Nishikawa $K$, et al. Substrate recognition of tRNA (Guanosine-2'-)-methyltransferase from Thermus thermophilus HB27. J Biol Chem 1998;273:25721-25727.

19. Hori H, Kubota S, Watanabe K, Kim JM, Ogasawara T, Sawasaki T, et al. Aquifex aeolicus tRNA (Gm18) methyltransferase has unique substrate specificity. TRNA recognition mechanism of the enzyme. J Biol Chem 2003;278: 25081-25090.

20. Ochi A, Makabe K, Yamagami R, Hirata A, Sakaguchi R, Hou $\mathrm{YM}$, et al. The catalytic domain of topological knot tRNA methyltransferase (TrmH) discriminates between substrate
tRNA and nonsubstrate tRNA via an induced-fit process. J Biol Chem 2013;288:25562-25574.

21. Jockel S, Nees G, Sommer R, Zhao Y, Cherkasov D, Hori H, et al. The 2'-O-methylation status of a single guanosine controls transfer RNA-mediated Toll-like receptor 7 activation or inhibition. J Exp Med 2012;209:235-241.

22. Li JN, Bjork GR. Structural alterations of the tRNA (m1G37)methyltransferase from Salmonella typhimurium affect tRNA substrate specificity. RNA 1999;5:395-408.

23. Liu J, Wang W, Shin DH, Yokota H, Kim R, Kim SH. Crystal structure of tRNA (m1G37) methyltransferase from Aquifex aeolicus at 2.6 A resolution: a novel methyltransferase fold. Proteins 2003;53:326-328.

24. Holmes WM, Andraos-Selim C, Roberts I, Wahab SZ. Structural requirements for tRNA methylation: action of Escherichia coli tRNA(guanosine-1)methyltransferase on tRNA (1Leu) structural variants. J Biol Chem 1992;267:1344013445.

25. Hagervall TG, Tuohy TM, Atkins JF, Björk GR. Deficiency of 1-methylguanosine in tRNA from Salmonella typhimurium induces frameshifting by quadruplet translocation. $J$ Mol Biol 1993;232:756-765.

26. Björk GR, Wikström PM, Byström AS. Prevention of translational frameshifting by the modified nucleoside 1-methylguanosine. Science 1989;244:986-989.

27. Lee C, Kramer G, Graham DE, Appling DR. Yeast mitochondrial initiator tRNA is methylated at guanosine 37 by the Trm5-encoded tRNA (guanine-N1-)-methyltransferase. J Biol Chem 2007;282:27744-27753.

28. Watanabe K, Nureki O, Fukai S, Ishii R, Okamoto H, Yokoyama $\mathrm{S}$, et al. Roles of conserved amino acid sequence motifs in the SpoU (TrmH) RNA methyltransferase family. J Biol Chem 2005;280:10368-10377.

29. GtRNAdb. Genomic tRNA Database, 2011. Accessed 2014 Jan 10. Available from: http://gtrnadb.ucsc.edu/.

30. BioEdit. Carlsbad: Tom Hall, c1997-2013. Accessed 2014 Jan 15. Available from: http://www.mbio.ncsu.edu/bioedit/ bioedit.html.

31. Srinivasan T, Kumaran K, Selvakumar R, Velmurugan D, Sudarsanam D. Exploring GpG bases next to anticodon in tRNA subsets. Bioinformation 2013;9:466-470.

32. Watanabe K, Nureki O, Fukai S, Endo Y, Hori H. Functional categorization of the conserved basic amino acid residues in TrmH (tRNA (Gm18) methyltransferase) enzymes. J Biol Chem 2006;281:34630-34639.

33. Björk GR, Jacobsson K, Nilsson K, Johansson MJ, Byström AS, Persson OP. A primordial tRNA modification required for the evolution of life? EMBO J 2001;20:231-239.

34. Goto-Ito S, Ito T, Ishii R, Muto Y, Bessho Y, Yokoyama S. Crystal structure of archaeal tRNA(m(1)G37)methyltransferase aTrm5. Proteins 2008;72:1274-1289.

35. Konevega AL, Soboleva NG, Makhno VI, Semenkov YP, Wintermeyer W, Rodnina MV, et al. Purine bases at position 37 of tRNA stabilize codon-anticodon interaction in the ribosomal A site by stacking and $\mathrm{Mg} 2+$-dependent interactions. RNA 2004;10:90-101. 